\title{
Clinico-radiological profile of connective tissue disease related-interstitial lung diseases from a tertiary care centre of India: a cross sectional study
}

\author{
Mehul Agarwal' ${ }^{1}$, Manohar Lal Gupta ${ }^{2}$, Kunal Deokar ${ }^{1}$, Benhur Joel Shadrach ${ }^{1}$, Neha Bharti ${ }^{3}$, \\ Maldev Sonigra ${ }^{1}$ \\ ${ }^{1}$ Department of Pulmonary Medicine, All India Institute of Medical Sciences, Jodhpur; ${ }^{2}$ Department of Pulmonary \\ Medicine, Santokba Durlabhji Memorial Hospital, Jaipur; ${ }^{3}$ Department of Anesthesia and Critical Care, All India \\ Institute of Medical Sciences, Jodhpur, India
}

\begin{abstract}
Interstitial lung diseases (ILDs) are a frequently occurring pulmonary manifestation in patients of connective tissue diseases (CTD). Detailed understanding of this subset of lung dis-
\end{abstract}

Correspondence: Benhur Joel Shadrach, Department of Pulmonary Medicine, All India Institute of Medical Sciences (AIIMS), Jodhpur, India.

Tel. +919655549072

E-mail: benjoe6326@gmail.com.

Keywords: Connective tissue diseases; interstitial lung diseases; spirometry; HRCT thorax; prognosis.

Contributions: MA, MLG, KD, BJS, concepts, MA, MLG, KD, BJS, design, MA, MLG, KD, BJS, definition of intellectual content, MA, $\mathrm{KD}$, BJS, NB, literature search, clinical studies, experimental studies, MA, KD, BJS, NB, MS, data acquisition, MA, KD, BJS, NB, MS, data analysis, MA, BJS, statistical analysis, MA, KD, BJS, NB, manuscript preparation, MA, MLG, KD, BJS, manuscript editing, MA, MLG, KD, $\mathrm{BJS}, \mathrm{NB}, \mathrm{MS}$, manuscript review, MA, KD, BJS, guarantor.

Funding: None.

Conflict of interest: The authors declare no potential conflict of interest.

Ethical approval: The study was approved by the Institutional ethics committee of Santokba Durlabhji Memorial Hospital, Jaipur, India.

Informed consent: Written informed consent was obtained from the patient to publish his/her clinical details and investigations. The patient understands that his/her name and initials will not be published but anonymity cannot be guaranteed.

Received for publication: 26 September 2020.

Accepted for publication: 22 March 2021.

${ }^{\circ}$ Copyright: the Author(s), 2021

Licensee PAGEPress, Italy

Monaldi Archives for Chest Disease 2021; 91:1624

doi: 10.4081/monaldi.2021.1624

This article is distributed under the terms of the Creative Commons Attribution Noncommercial License (by-nc 4.0) which permits any noncommercial use, distribution, and reproduction in any medium, provided the original author(s) and source are credited. eases is vital, hence the study was conducted to analyze the clinico-radiological characteristics of CTD-ILD. The present study was conducted between March 2017 to February 2018 at a tertiary care teaching hospital from western India. A total of 100 patients having respiratory symptoms suggestive of ILD, who were either diagnosed cases of CTD or had clinical manifestations of underlying CTD, were included in the study. Twentyseven percent of patients belonged to age group 41-50 years and $78 \%$ were females. Chief respiratory complaints were dyspnea and cough. Clubbing was present in $29 \%$ patients. The most common CTDs were rheumatoid arthritis (RA) (26\%), systemic sclerosis (SSC) (21\%), mixed connective tissue disorder (MCTD) (19\%) and Sjogren's syndrome (SS) (16\%). Restrictive defect on spirometry was seen in $58 \%$ cases and was most significant among patients with RA (65\%) and SS (62\%). Pulmonary arterial hypertension was seen in $40 \%$ cases and was most evident in MCTD (78\%) and SSC patients (58\%). Chest radiograph was normal in $47 \%$ of subjects. Most common radiological pattern on high resolution computed tomography (HRCT) thorax was non-specific interstitial pneumonia $(42 \%)$ followed by usual interstitial pneumonia (21\%). ILD is a common manifestation of CTD. Work-up for an underlying CTD should be offered to all ILD patients and vice versa.

\section{Introduction}

Interstitial lung diseases (ILD) are a basket of 200 different disorders with diverse underlying etiological factors and with common features of varying degrees of fibrosis and inflammation of lung parenchyma and/or interstitium. Connective tissue diseases (CTDs) are inflammatory disorders with autoimmune mechanism and frequently involves the lung along with other organs of the body [1]. CTDs can involve any component of the respiratory system including the airways and pleura leading to ventilatory impairments, pulmonary vasculature resulting in vasculitis and/or pulmonary hypertension, and fibro-inflammatory parenchymal abnormalities [2]. Common CTDs presenting with ILDs include rheumatoid arthritis (RA), systemic sclerosis (SSC), Sjogren's syndrome (SS), mixed connective tissue disorder (MCTD), systemic lupus erythematosus (SLE), and polymyositis (PM)/ dermatomyositis (DM). In majority of the cases, patients are already diagnosed with some form of CTD when ILD is recognized, however in a few subsets of CTDs pulmonary manifestations tend to precede the clinical signs and symptoms of CTDs [3]. CTD-ILDs carry a better overall prog- 
nosis compared to other common ILDs like idiopathic pulmonary fibrosis (IPF) Hence, the present study, first of its kind from western India, was conducted to recognize the clinico-radiological profile of pulmonary involvement associated with different forms of CTDs, which may impact survival of these patients.

\section{Materials and Methods}

\section{Study design and setting}

The study was conducted between March 2017 and February 2018 , in the department of pulmonary medicine of a tertiary care teaching hospital of western India. It was a prospective, crosssectional, observational study. Subjects included in the study belonged to two categories. These include previously diagnosed cases of CTD who presented with pulmonary signs and symp- toms of an underlying ILD and patients of ILD with a clinical suspicion of CTD which was later confirmed. Pregnant females, less than 18 years of age, patients with active infections and comorbidities including congestive heart failure, renal and liver failure and not giving informed written consent were excluded. After fulfilling the inclusion and having none of the exclusion criteria, a total of 118 patients were enrolled in our study. Five patients later withdrew consent, 8 patients with clinical suspicion of CTD were found to have infectious etiology, 2 had malignancy, 2 had only CTD without lung involvement/ILD and their respiratory symptoms were due to unrelated respiratory tract infection, 2 were lost to follow up and 1 succumbed due to massive pulmonary embolism. Finally, 100 patients were included (Figure 1). These patients after detailed clinical history and examination were evaluated by spirometry, body plethysmography, doppler echocardiogram, chest radiograph, HRCT thorax, and tests for immunological work-up were sent, as per requirement. HRCT

118 cases of suspected/confirmed cases of CTD ILD enrolled

after initial screening

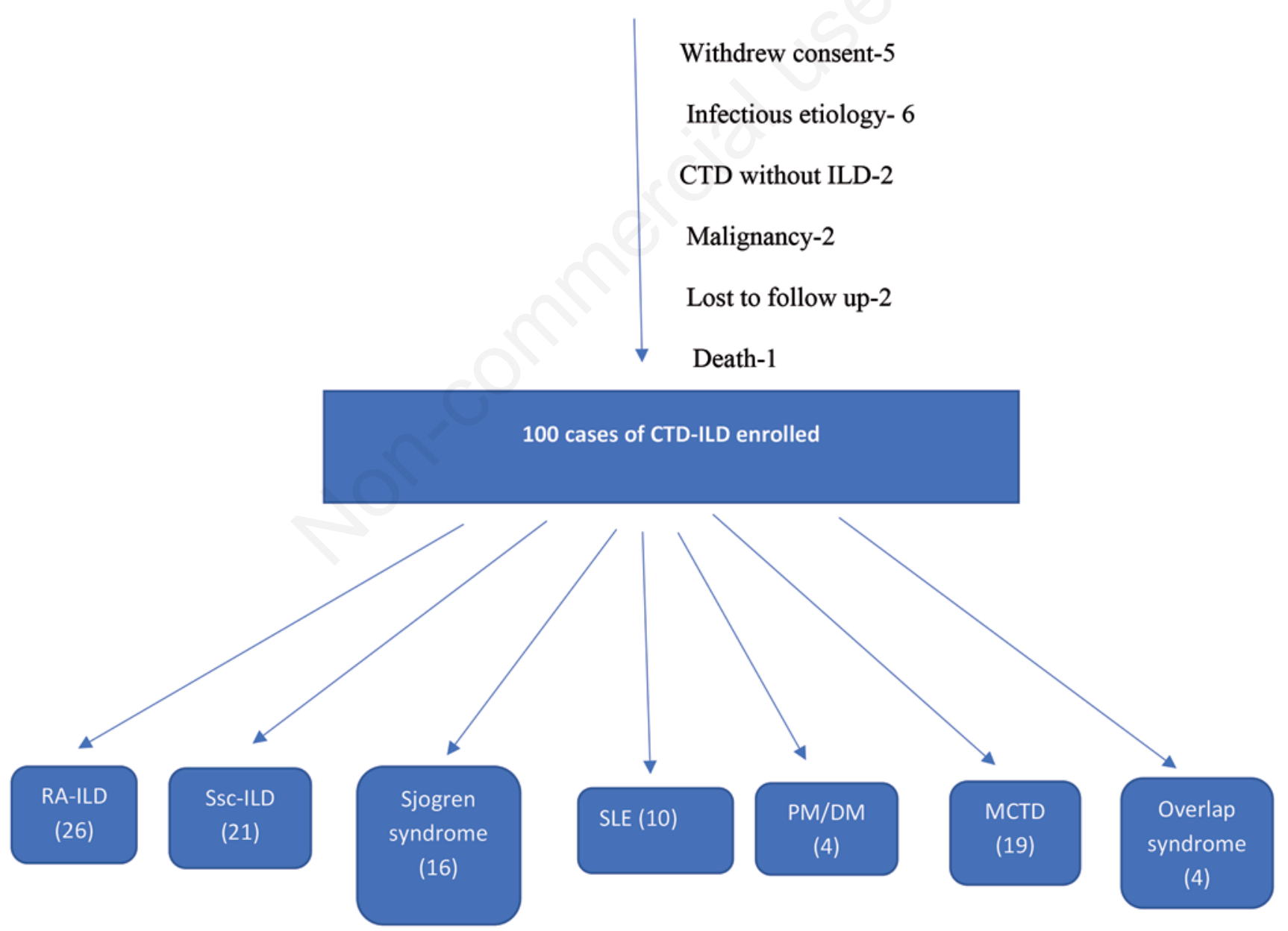

Figure 1. Flow chart depicting recruitment of cases and the various connective tissue diseases (CTD) - interstitital lung diseases (ILD) in our study population. RA, rheumatoid arthritis; SSC, systemic sclerosis; SLE, systemic lupus erythematosus; PM/DM, polymyositis/dermatomyositis; MCTD, mixed connective tissue disease. 
thorax was done by Optima, General Electronics. Sixty-four slices with $1.25 \mathrm{~mm}$ thickness were acquired as per the recommended scanning protocol for interstitial lung disease [4]. Spirometry graph plotting was done with HELLO'S software which uses the same standardization values of the updated 1993 statement of the European Respiratory Society [5]. Doppler echocardiogram to calculate pulmonary artery systolic pressure (PASP) was done by tricuspid regurgitation (TR) peak velocity method. Symptomatology, signs, functional tests and type of pleuro-parenchymal disease were then correlated in context of background connective tissue disorder.

\section{Definitions}

- Obstructive ventilatory impairment in spirometry is defined by the ratio of forced expiratory volume in the first second $\left(\mathrm{FEV}_{1}\right)$ /forced vital capacity $(\mathrm{FVC})<70$ of lower limit of normal and $\mathrm{FVC}>80 \%$ of predicted.

- Restrictive ventilatory impairment was defined by FVC $<80 \%$ of predicted in spirometry and total lung capacity (TLC) $<80 \%$ of predicted via body plethysmography.

- Mixed ventilatory defect was given by $\mathrm{FEV}_{1} / \mathrm{FVC}<70$ as well as FVC and TLC less than $80 \%$ of predicted.

- Pulmonary hypertension was defined by PASP more than $35 \mathrm{mmhg}$ doppler echocardiogram by TR peak velocity method.

\section{Statistical Analysis}

Descriptive statistics were used to describe baseline characteristics. Quantitative variables were presented as mean and standard deviation. Dichotomous variables were presented as number and percentages. Chi square test was applied and p-value $<0.05$ was considered significant. All the statistical calculations were performed using STATA 12 [STATA Corp. TX, USA] statistical software.

\section{Results}

The majority of the patients $(78 \%)$ in the study population were females and $50 \%$ patients belonged to age group between 40 to 60 years of age with a mean age of $45.69 \pm 13.04$ years. In our study, patients with SSC and SLE were all females while there were all males in PM/DM group (Figure 2). As depicted in Table 1, most frequent respiratory symptoms were dyspnea seen in all patients with RA, SSC, SS and PM/DM while cough was present in all patients with PM/DM, MCTD and overlap syndrome. Hemoptysis was seen in one patient with SLE while chest pain was most evident in patients with SLE (40\%) and MCTD $(36.8 \%)$.

Among the rheumatological symptoms (Table 1), joint pain was the most common in patients with RA (96.1\%), PM/DM (75\%) and overlap syndrome (75\%). History of joint swelling (88.4\%) and morning stiffness $(80.7 \%)$ was most frequent among patients with RA. Ninety percent of patients with SSC had history of Raynaud's phenomenon. Muscle pain was mostly seen in patients with PM/DM (52.6\%) and MCTD (50\%) while $70 \%$ of patients with SLE had facial swelling. All these findings were statistically significant.

In physical examination (Table 1), 29\% had clubbing, 69\% had velcro crepitations on auscultation, some form of oral and skin lesions was seen in $30 \%$ and $27 \%$ of the patients, respectively. Majority of the patients (58\%) had restrictive defect on spirometry and body plethysmography and was most frequent in patients with overlap syndrome (100\%), RA (65.3\%) and SS (62.5\%), as depicted in Table 2. Raised PASP $(>35 \mathrm{mmHg}$ ) was seen in $40 \%$ of study subjects and was most evident in MCTD (78.95\%) and SSC (54.14\%) groups (Table 2).

Chest radiograph was normal in $47 \%$ of study subjects. HRCT pattern among various CTDs is shown in Table 2. Nonspecific interstitial pneumonia (NSIP) (42\%) was the most common pattern followed by usual interstitial pneumonia (UIP)

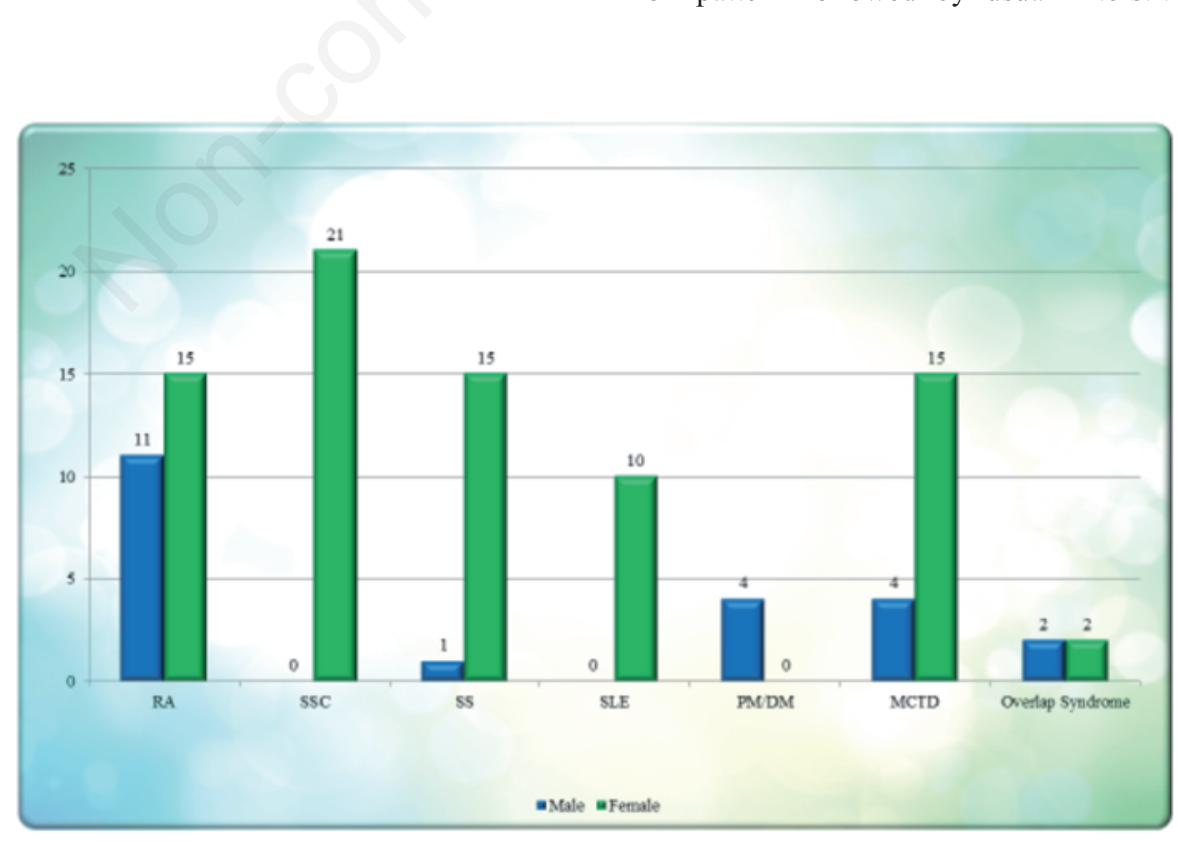

Figure 2. Gender distribution among various connective tissue diseases (CTD) in the study population. RA, rheumatoid arthritis; SSC, systemic sclerosis; SLE, systemic lupus erythematosus; PM/DM, polymyositis/dermatomyositis; MCTD, mixed connective tissue disease. 
(21\%). NSIP was commonly seen in patients with SSC (66.6\%), MCTD (52.6\%) and SS (43.7\%) while UIP (38.4\%) was the predominant pattern in patients with RA. Organizing pneumonia and bronchiolitis were the other patterns distributed among the study subjects. Seventy five percent of patients with PM/DM had ground glass opacities with pleural effusion. Lymphocytic interstitial pneumonia (LIP) and necrobiotic nodules were seen in one patient each with Sjogren's and RA, respectively. Figure 3A-F: Figure $3 \mathrm{~A}-\mathrm{F}$ shows HRCT thorax images of various ILD patterns associated with CTD seen in our patients.

Table 1. Respiratory, rheumatological symptoms and physical findings associated with various connective tissue diseases (CTD).

\begin{tabular}{|c|c|c|c|c|c|c|c|c|}
\hline Parameters & $\begin{array}{c}\text { RA } \\
(n=26)\end{array}$ & $\begin{array}{c}\text { SSC } \\
(n=21)\end{array}$ & $\begin{array}{l}\text { Sjogren's } \\
\text { syndrome } \\
(\mathrm{n}=16)\end{array}$ & $\begin{array}{c}\text { SLE } \\
(n=10)\end{array}$ & $\begin{array}{l}\text { PM/DM } \\
(\mathrm{n}=4)\end{array}$ & $\begin{array}{c}\text { MCTD } \\
(\mathrm{n}=19)\end{array}$ & $\begin{array}{l}\text { Overlap } \\
\text { syndrome } \\
(\mathrm{n}=4)\end{array}$ & p-value \\
\hline $\begin{array}{l}\text { Respiratory symptoms } \\
\text { Cough } \\
\text { Dyspnea } \\
\text { Hemoptysis } \\
\text { Chest pain }\end{array}$ & $\begin{array}{l}25(96.1) \\
26(100) \\
0 \\
3(11.5)\end{array}$ & $\begin{array}{l}20(95.2) \\
21(100) \\
0 \\
2(9.5)\end{array}$ & $\begin{array}{c}15(93.7) \\
16(100) \\
0 \\
0\end{array}$ & $\begin{array}{l}8(80) \\
9(90) \\
1(10) \\
4(40)\end{array}$ & $\begin{array}{l}4(100) \\
4(100) \\
0 \\
0\end{array}$ & $\begin{array}{c}19(100) \\
18(94.7) \\
0 \\
7(36.8)\end{array}$ & $\begin{array}{l}4(100) \\
3(75) \\
0 \\
0\end{array}$ & $\begin{array}{c}0.43 \\
0.06 \\
0.18 \\
0.019\end{array}$ \\
\hline $\begin{array}{l}\text { Rheumatological symptoms } \\
\text { Joint pain } \\
\text { Joint swelling } \\
\text { Morning stiffness } \\
\text { Raynaud's } \\
\text { Muscle pain } \\
\text { Facial swelling }\end{array}$ & $\begin{array}{c}25(96.1) \\
23(88.4) \\
21(80.7) \\
0 \\
0 \\
1(3.8)\end{array}$ & $\begin{array}{c}9(42.8) \\
1(4.7) \\
0 \\
19(90.4) \\
1(4.7) \\
2(9.5)\end{array}$ & $\begin{array}{c}5(31.2) \\
0 \\
0 \\
0 \\
0 \\
0\end{array}$ & $\begin{array}{c}4(40) \\
4(40) \\
0 \\
0 \\
0 \\
7(70)\end{array}$ & $\begin{array}{c}3(75) \\
0 \\
0 \\
0 \\
2(50) \\
0\end{array}$ & $\begin{array}{c}12(63.1) \\
4(21) \\
0 \\
0 \\
10(52.6) \\
8(42.1)\end{array}$ & $\begin{array}{l}3(75) \\
2(50) \\
0 \\
2(50) \\
1(25) \\
1(25)\end{array}$ & $\begin{array}{l}<0.01 \\
<0.01 \\
<0.01 \\
<0.01 \\
<0.01 \\
<0.01\end{array}$ \\
\hline $\begin{array}{l}\text { Physical findings } \\
\text { Clubbing } \\
\text { Joint tenderness /deformity } \\
\text { Oral cavity }\end{array}$ & $\begin{array}{c}11(42.3) \\
1(3.8)\end{array}$ & $\begin{array}{c}9(42.8) \\
0\end{array}$ & $\begin{array}{c}6(37.5) \\
0\end{array}$ & $\begin{array}{l}0 \\
0\end{array}$ & $\begin{array}{l}0 \\
0\end{array}$ & $\begin{array}{c}1(5.2) \\
0\end{array}$ & $\begin{array}{c}2(50) \\
0\end{array}$ & $\begin{array}{l}<0.05 \\
>0.05\end{array}$ \\
\hline $\begin{array}{l}\text { Microstomia } \\
\text { Ulcers } \\
\text { Stomatitis }\end{array}$ & $\begin{array}{l}0 \\
0 \\
0\end{array}$ & $\begin{array}{l}6(28.5) \\
7(33.3) \\
2(9.5)\end{array}$ & $\begin{array}{c}2(12.5) \\
4(25) \\
0\end{array}$ & $\begin{array}{c}0 \\
2(20) \\
0\end{array}$ & $\begin{array}{l}0 \\
0 \\
0\end{array}$ & $\begin{array}{c}1(5.2) \\
3(15.7) \\
0\end{array}$ & $\begin{array}{l}1(25) \\
2(50) \\
0\end{array}$ & $\begin{array}{l}>0.05 \\
>0.05\end{array}$ \\
\hline $\begin{array}{l}\text { Cutaneous signs } \\
\text { Rashes } \\
\text { Dryness } \\
\text { Hypopigmented patch } \\
\text { Excoriation }\end{array}$ & $\begin{array}{c}1(3.8) \\
0 \\
0 \\
0\end{array}$ & $\begin{array}{l}8(38) \\
2(9.5) \\
0 \\
0\end{array}$ & $\begin{array}{c}3(18.7) \\
5(31.2) \\
0 \\
0\end{array}$ & $\begin{array}{c}3(30) \\
0 \\
0 \\
0\end{array}$ & $\begin{array}{c}1(25) \\
0 \\
0 \\
0\end{array}$ & $\begin{array}{c}0 \\
1(5.2) \\
1(5.2) \\
1(5.2)\end{array}$ & $\begin{array}{c}1(25) \\
0 \\
0 \\
0\end{array}$ & $\begin{array}{c}>0.05 \\
>0.05 \\
>0.05 \\
0.05\end{array}$ \\
\hline Velcro crepitation & $19(73)$ & $17(80.9)$ & 13 (81.2) & $2(20)$ & $1(25)$ & 13 (68.4) & $4(100)$ & 0.067 \\
\hline Xerophthalmia & 0 & 0 & $2(12.5)$ & 0 & 0 & 0 & 0 & 0.13 \\
\hline
\end{tabular}

RA, rheumatoid arthritis; SSC, systemic sclerosis; SLE, systemic lupus erythematosus; PM/DM, polymyositis/dermatomyositis; MCTD, mixed connective tissue disease; values in parenthesis indicates percentage.

Table 2. Spirometry, pulmonary hypertension and high-resolution computed tomography findings associated with various connective tissue diseases (CTD) in the study population.

\begin{tabular}{|c|c|c|c|c|c|c|c|c|}
\hline Parameters & $\begin{array}{c}\mathrm{RA} \\
(n=26)\end{array}$ & $\begin{array}{c}\text { SSC } \\
(n=21)\end{array}$ & $\begin{array}{c}\text { Sjogren's } \\
\text { syndrome } \\
(\mathrm{n}=16)\end{array}$ & $\begin{array}{c}\text { SLE } \\
(n=10)\end{array}$ & $\begin{array}{r}\text { PM/DM } \\
(n=4)\end{array}$ & $\begin{array}{c}\text { MCTD } \\
(n=19)\end{array}$ & $\begin{array}{l}\text { Overlap } \\
\text { syndrome } \\
(\mathrm{n}=4)\end{array}$ & p-value \\
\hline \multicolumn{9}{|c|}{ Pulmonary function abnormality } \\
\hline Mixed defects & $3(11.5)$ & $6(28.5)$ & $2(12.5)$ & $4(40)$ & $1(25)$ & $3(15.7)$ & 0 & 0.37 \\
\hline Restriction & $17(65.3)$ & $13(61.9)$ & $10(62.5)$ & $3(30)$ & $1(25)$ & $10(52.6)$ & $4(100)$ & 0.18 \\
\hline Obstruction & $6(23)$ & $2(9.5)$ & $4(25)$ & $3(30)$ & $2(50)$ & $6(31.5)$ & 0 & 0.43 \\
\hline \multicolumn{9}{|l|}{ Pulmonary hypertension } \\
\hline \multicolumn{9}{|l|}{ HRCT pattern } \\
\hline UIP & $10(38.46)$ & $3(14.29)$ & $2(12.50)$ & 0 & 0 & $3(15.79)$ & $2(50)$ & 0.05 \\
\hline Probable UIP & 0 & 0 & 0 & 0 & 0 & 0 & $1(25)$ & 0.002 \\
\hline NSIP & $8(30.77)$ & $14(66.67)$ & $7(43.75)$ & $1(10)$ & $1(25)$ & $10(52.63)$ & $1(25)$ & 0.05 \\
\hline Organizing pneumonia & $4(15.38)$ & $4(19.05)$ & $5(31.25)$ & $2(20)$ & 0 & $4(21.05)$ & 0 & 0.73 \\
\hline Bronchiolitis & $2(7.8)$ & 0 & $1(6.25)$ & $3(30)$ & 0 & $1(5.26)$ & 0 & 0.13 \\
\hline GGO with effusion & $1(3.8)$ & 0 & 0 & $4(40)$ & $3(75)$ & 0 & 0 & $<0.001$ \\
\hline LIP & 0 & 0 & $1(6.25)$ & 0 & 0 & 0 & 0 & 0.52 \\
\hline Necrobiotic nodule & $1(3.85)$ & 0 & 0 & 0 & 0 & 0 & 0 & 0.84 \\
\hline
\end{tabular}

RA, rheumatoid arthritis; SSC, systemic sclerosis, SLE, systemic lupus erythematosus, PM/DM, polymyositis/dermatomyositis, MCTD, mixed connective tissue disease; UIP, usual interstitial pneumonia; NSIP, nonspecific interstitial pneumonia; GGO, ground glass opacity; HRCT, high-resolution computed tomography; LIP, lymphocytic interstitial pneumonia. 


\section{Discussion}

The most common CTDs associated with ILD in our study were RA (26\%) and SSC (21\%). Several other studies also had RA and SSC as the most common CTDs associated with ILD [6-8]. Restrictive defect was seen in $58 \%$ of the patients. In a study by Verma et al., $62.4 \%$ of patients of CTD with respiratory symptoms had restrictive pattern [7]. Similar observations were made by Gaude et al, where $60 \%$ of the patients had restrictive defect [9]. NSIP pattern was the common pattern on HRCT thorax seen in nearly $40 \%$ of our study population. UIP pattern was the most common pattern in patients with RA (38.46\%). Two landmark Indian studies of Singh et al. [10] and Kumar et al. [11] respectively had comparable results similar to our study. In study by Singh et al. they recruited a total of 1,084 patients with ILD from 27 centers across India, of these 151 (13.9\%) were CTD-ILD. Among patients with CTD-ILD, the commonest presenting symptom was dyspnea (90.9\%) while $82.2 \%$ experienced cough at presentation. Mean age was 50.8 years and most were women $(73.5 \%)$. A total of $54.3 \%$ had NSIP, whereas $31.8 \%$ had UIP. Rheumatoid arthritis was the most common specific CTD (38.4\%) followed by scleroderma (22.5\%). Kumar et al. enrolled 289 patients with ILD in their study, of which 13 were diagnosed with CTD-ILD. Mean age at presentation was 44.24 years; females comprised $54.68 \%$ of the patients. The most frequent presenting symptom cough $(92.7 \%)$, followed by exertional dyspnea (79.2\%). Of 13 patients, 6 cases were each of RA and SSC. NSIP was most common pattern of ILD on HRCT.

Among 26 patients with RA, predominant symptoms included cough, breathlessness, joint pain/swelling, and morning stiffness. Nearly two-third of RA patients had restrictive ventilatory defect. Prevalence of pulmonary hypertension was less (19.2\%) among patients with RA. This is in line with previous studies which showed a lower prevalence of pulmonary hypertension in RA patients when compared with other CTDs-ILD $[12,13]$. Most common HRCT pattern among patients with RA was UIP (38\%). Other studies are also in concordance with our findings $[9,14]$. Pleural effusion was present in $3.8 \%$ of subjects. In a study by Shannon et al. they found incidence of pleural effusion to be around $5 \%$ in patients with RA [15].

Among the patients with SSC, nearly all patients had cough and breathlessness. Ninety percent patients had history of Raynaud's phenomenon. Raynaud's phenomenon was seen in $75 \%$ of SSC patients in a registry analysis [16]. Restrictive defect on spirometry was seen in $61.9 \%$ while pulmonary hypertension was present in $54 \%$ of cases. NSIP was the most common pattern $(66.6 \%)$ observed on HRCT thorax. Similar findings were observed in previous studies from this part of the world $[12,13]$.

NSIP was the most common pattern among patients with

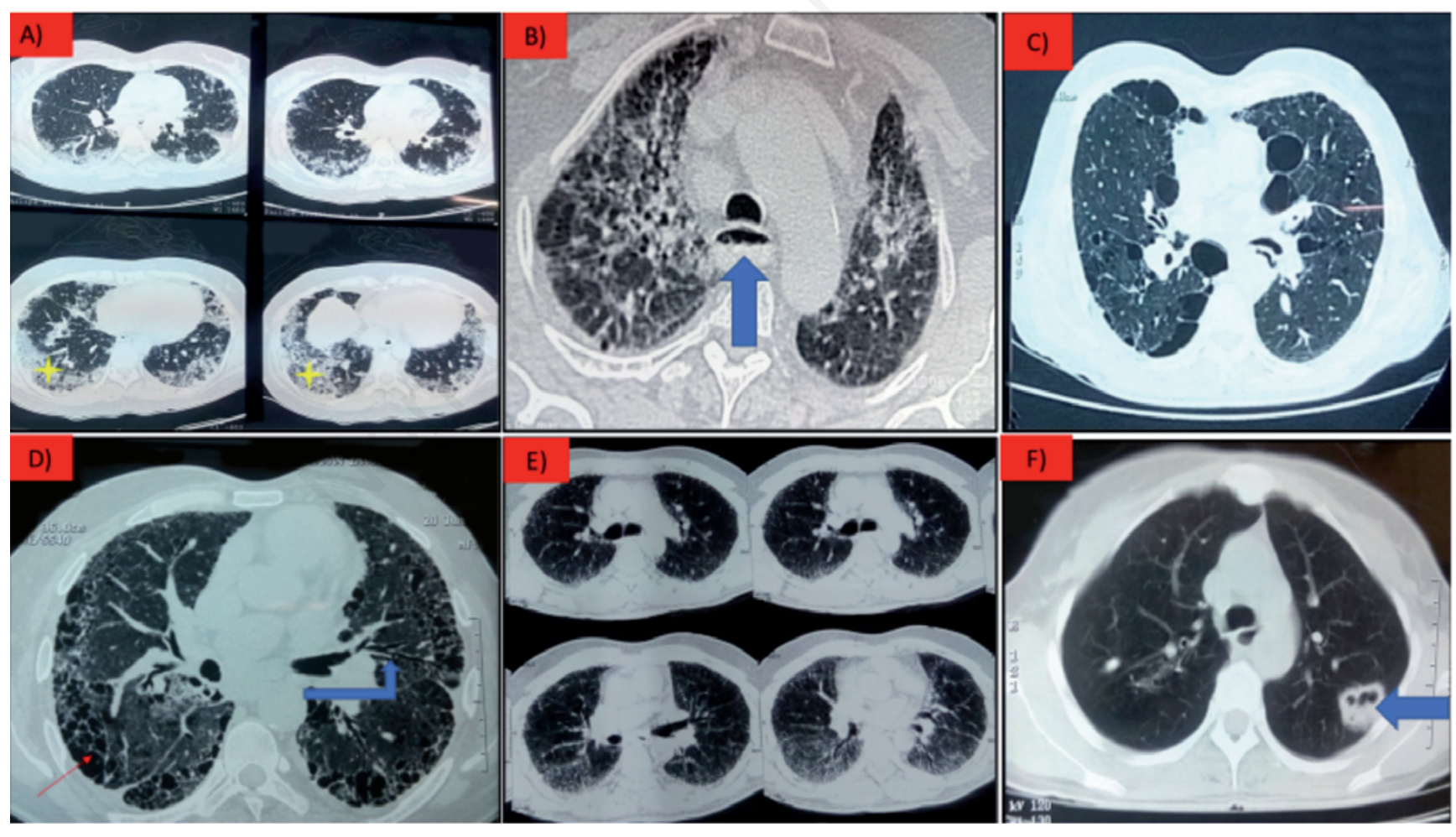

Figure 3. A) High-resolution computed tomography (HRCT) thorax axial reformatted images lung window shows bilateral patchy peripheral peribronchovascular subpleural consolidation and ground glass opacity (GGO) (yellow asterisk) in a case of polymyositis (PM) / dermatomyositis (DM) suggestive of organizing pneumonia. B) Dilated esophagus in a patient with systemic sclerosis (SSC) interstitial lung disease (ILD) with fibrotic non-specific interstitial pneumonia (NSIP) pattern (blue arrow). C) Lymphocytic interstitial pneumonia (LIP) in a patient with Sjogren syndrome (SS). D) Usual interstitial pneumonia (UIP) pattern seen in a case of RA-interstitial lung disease (ILD); computed tomography (CT) axial reformatted images at the level of inferior pulmonary vein shows bilateral basal subpleural multilayered cysts stacked upon one other referred to as honeycombing (red arrow) and traction bronchiectasis (blue arrow). E) Depicting NSIP pattern in a case of SSC-ILD. F) Necrobiotic nodules in a patient with rheumatoid arthritis (RA) with a single nodule undergoing cavitation (blue arrow). 
MCTD (52.6\%) and SS (43.7\%) in the present study. As per a previous study, this pattern is the most common radiologic and histologic pattern in patients with SSC, PM/DM and MCTD [17]. Among patients with SS, joint pain (31.2\%) was the only rheumatological symptom while dry eyes were present in two patients. Misra et al. also observed sicca symptom and arthralgia as common presenting rheumatological features [18]. Incidence of PAH was very low $(12.5 \%)$ while $62.5 \%$ had restrictive defect on spirometry in patients with SS. Organizing pneumonia was the most common pattern $(31.2 \%)$ after NSIP $(43.7 \%)$ while UIP pattern was seen in two and LIP in one patient. Similar observations were noted in a study by Ito et al. [19].

Along with cough and breathlessness, $40 \%$ of the patients with SLE also had chest pain as chief respiratory complaint. Facial swelling was present in $70 \%$ of the patients in our study. Restrictive ventilatory defect was seen in $30 \%$ cases. These findings are in concordance with studies by Kakati and Weinribet et al. [20,21]. Pulmonary hypertension was seen in $10 \%$ cases as was also seen in studies by Verma and Gaude et al. [7,9]. HRCT thorax showed ground glass opacity (GGO) with effusion in $40 \%$ cases and bronchiolitis in $30 \%$ cases. This is in contrast to findings of the study by Verma et al. where NSIP was the most common pattern on HRCT [7]. Quadrelli et al. in their study found pulmonary hemorrhage $(25.5 \%)$ as the common feature on HRCT in SLE patients [22].

Cough and dyspnea were seen in all patients with PM/DM while joint pain was seen in $75 \%$ and myalgia in $50 \%$ of cases. All patients with PM/DM were males in our study. Douglas et al. also made similar clinical observations in their study of 70 patients with PM/DM [23]. Similar to SLE group, patients with PM/DM also had lesser incidence of pulmonary hypertension and restrictive abnormality, as was also seen in study done by Gaude et al. [9]. This group also had GGO with effusion as the common HRCT abnormality seen in $75 \%$ cases.

In MCTD group, nearly all patients had dyspnea and cough. Joint pain (63.1\%), myalgia (52.6\%), facial swelling (42.1\%) and chest pain $(36.8 \%)$ were other common symptoms. Both SSC and MCTD group had higher incidence of pulmonary hypertension (78.9\%) and restrictive defect on PFT (52.6\%) in our study. NSIP $(52.6 \%)$ and organizing pneumonia $(21 \%)$ were common HRCT patterns observed. Similar observations were seen in studies by both Verma and Gaude et al. [7,9].

Our study had few limitations. The sample size was relatively small and was a single centre experience. Diffusing lung capacity for carbon monoxide (DLCO) were not measured in our patients which could have helped in early identification of lung and pulmonary vascular involvement especially in those with apparently normal pulmonary function tests. Finally, in patients with organizing pneumonia radiological pattern, bronchoscopy was not performed to rule out active infection before labelling as ILD

\section{Conclusions}

The common symptoms of CTD-ILDs include dry cough and exertional dyspnea. Detailed history, symptom evaluation, physical examination, pulmonary function tests, and HRCT thorax aids in diagnosis of CTD-ILDs. Clinicians should keep a high index of suspicion for CTD-ILD as it is a potentially reversible entity and carries a better prognosis to appropriate therapy than idiopathic fibrosing ILDs which are generally associated with worse outcomes. NSIP pattern is the most common pattern observed in
CTD-ILDs, except in RA-ILD where UIP is the most common pattern. Incidence of pulmonary hypertension is higher in SSC and MTCD. LIP is seen in SS. Necrobiotic nodules are seen in RA.

\section{References}

1. Antoniou KM, Margaritopoulos G, Economidou F, Siafakas NM. Pivotal clinical dilemmas in collagen vascular diseases associated with interstitial lung involvement. Eur Respir J 2009;33:882-96.

2. Gutsche M, Rosen GD, Swigris JJ. Connective tissue diseaseassociated interstitial lung disease: A review. Curr Respir Care Rep 2012;1:224-32.

3. Ysamat Marfá R, Benito Ysamat A, Espejo Pérez S, et al. Lung disease associated with connective tissue disease. Radiologia 2013;5:107-17.

4. Quanjer PH, Tammeling GJ, Cotes JE, et al. Lung volumes and forced ventilatory flows. Report Working Party Standardization of Lung Function Tests, European Community for Steel and Coal. Official Statement of the European Respiratory Society. Eur Respir J Suppl 1993;16:5-40.

5. Raghu G, Remy-Jardin M, Myers JL, et al. Diagnosis of idiopathic pulmonary fibrosis. An official ATS/ERS/JRS/ALAT clinical practice guideline. Am J Respir Crit Care Med 2018;198:e44-68.

6. Navaratnam V, Ali N, Smith CJ, McKeever T, Fogarty A, Hubbard RB. Does the presence of connective tissue disease modify survival in patients with pulmonary fibrosis? Respir Med 2011;105:1925-30.

7. Verma SK, Saheer S, Kumar P, et al. Respiratory manifestations among patients with connective tissue disorders. J Indian Acad Clin Med 2013;14:28-32.

8. de Lauretis A, Veeraraghavan S, Renzoni E. Review series: Aspects of interstitial lung disease: connective tissue diseaseassociated interstitial lung disease: how does it differ from IPF? How should the clinical approach differ? Chron Respir Dis 2011;8:53-82.

9. Gaude GS, Mahishale V, Srivastava A. Pulmonary manifestations in connective tissue disorders: hospital-based study at a tertiary care hospital. Indian J Chest Dis Allied Sci 2009;51:145-51.

10. Singh S, Collins BF, Sharma BB, et al. Interstitial lung disease in India. Results of a prospective registry. Am J Respir Crit Care Med 2017;195:801-13.

11. Kumar R, Gupta N, Goel N. Spectrum of interstitial lung disease at a tertiary care centre in India. Pneumonol Alergol Pol 2014;82:218-26.

12. Udayakumar N, Venkatesan S, Rajendiran C. Pulmonary hypertension in rheumatoid arthritis - relation with the duration of the disease. Int J Cardiol 2008;127:410-12.

13. Tanaka N, Kim JS, Newell JD, et al. Rheumatoid arthritis-related lung diseases: CT findings. Radiology 2004;232:81-91.

14. Lee HK, Kim DS, Yoo B, et al. Histopathologic pattern and clinical features of rheumatoid arthritis-associated interstitial lung disease. Chest 2005;127:2019-27.

15. Shannon TM, Gale ME. Noncardiac manifestations of rheumatoid arthritis in the thorax. J Thorac Imaging 1992;7:19-29.

16. Meier FM, Frommer KW, Dinser R, et al. Update on the profile of the EUSTAR cohort: an analysis of the EULAR Scleroderma Trials and Research group database. Ann Rheum Dis 2012;71:1355-60. 
17. Serra G, Brun AL, Ialongo P, et al. Thoracic involvement in connective tissue diseases: Radiological patterns and followup. JBR-BTR 2015;98:3-19.

18. Misra R, Hissaria P, Tandon V, et al. Primary Sjogren's syndrome: rarity in India. J Assoc Physicians India 2003;51:859-62.

19. Ito I, Nagai S, Kitaichi M, et al. Pulmonary manifestations of primary Sjogren's syndrome: a clinical, radiologic, and pathologic study. Am J Respir Crit Care Med 2005;171:632-8.

20. Kakati S, Doley B, Pal S, Deka UJ. Pulmonary manifestations in systemic lupus erythematosus (SLE) with special reference to HR CT. J Assoc Physicians India 2007;55:839-41. 21. Weinrib L, Sharma OP, Quismorio FP Jr. A long-term study of interstitial lung disease in systemic lupus erythematosus. Semin Arthritis Rheum 1990;20:48-56.

22. Quadrelli SA, Alvarez C, Arce SC, et al. Pulmonary involvement of systemic lupus erythematosus: analysis of 90 necropsies. Lupus 2009;18:1053-60.

23. Douglas WW, Tazelaar HD, Hartman TE, et al. Polymyositisdermatomyositis-associated interstitial lung disease. Am J Respir Crit Care Med 2001;164:1182-5. 